\title{
Amount Recovered Over Dosing Interval Normalized by Surface Area
}

National Cancer Institute

\section{Source}

National Cancer Institute. Amount Recovered Over Dosing Interval Normalized by

Surface Area. NCl Thesaurus. Code C102365.

The cumulative amount recovered from the specimen type specified in PPSPEC between doses (TAU) divided by surface area. 